\title{
Jovens estudantes e visitas em espaços públicos e culturais: engajamento, trans-formação do habitus e construção de sentidos
}

\begin{abstract}
Resumo:
Este artigo compartilha reflexões construídas a partir da pesquisa de doutorado em Psicologia Social que investigou a prática de visitação de jovens estudantes de escolas públicas a instituições artísticas e culturais da Região Metropolitana de Belo Horizonte. O acesso aos espaços públicos e culturais e às manifestações artísticas está situado historicamente tanto na perspectiva das legislações relativas às políticas públicas quanto nas práticas culturais de instituições que possibilitam acesso e experiências com as artes em equipamentos culturais. Considerando os jovens como sujeitos históricos e sujeitos de direitos, tomamos em consideração os sentidos e rígidos a partir das entrevistas e conversas realizadas com os jovens estudantes que participaram das visitas. Esses sentidos foram compreendidos por meio de uma abordagem fenomenológica que, em suas análises, articulou as contribuições teóricas de Pierre Bourdieu e de Arnold Berleant, relativas aos conceitos de habitus, campo estético e capital cultural. Na situação social pesquisada, a prática de visitação, o engajamento estético do observador-agente desponta como possibilidade de os jovens exercitarem a reflexividade, interrogarem e integrarem experiências construindo sentidos que tanto afirmam a potencialidade das visitas possibilitarem o acesso aos direitos culturais como operarem na afirmação e construção do habitus.
\end{abstract}

\section{Palavras-chave:}

Jovens. Direitos. Espaços culturais. Habitus. Psicologia Social.

\section{Young students and visits in public and cultural spaces: engage- ment, trans-formation of habitus and construction of meanings}

\footnotetext{
Abstract: This article shares reflections built from the doctoral research in Social Psychology that investigated the practice of visiting young students from public schools to artistic and cultural institutions in the Metropolitan Region of Belo Horizonte. Access to public and cultural spaces and artistic manifestations are historically situated both from the perspective of legislation related to public policies

1 Doutora em Psicologia, Professora do Centro Universitário UNA-BH. E-mail: cerisealvarenga@yahoo.com.br. ORCID iD: http://orcid.org/0000-0002-3228-5181.

2 Doutor em Psicologia Social, Professor da Universidade de São Paulo. E-mail: arley@usp.br. ORCID iD: https://orcid.org/0000-0002-8662-1646.
} 
and in the cultural practices of institutions that provide access and experiences with the arts in cultural facilities. Considering young people as historical subjects and subjects with rights, we take into account the meanings raised from the interviews and conversations conducted with the young students who participated in the visits. These meanings were understood through a phenomenological approach that, in their analysis, articulated the theoretical contributions of Pierre Bourdieu and Arnold Berleant, related to the concepts of habitus, aesthetic field and cultural capital. In the researched social situation, the practice of visitation, the aesthetic engagement of the observer-agent emerges as a possibility for young people to exercise reflexivity, interrogate and integrate experiences, constructing meanings that both affirm the potential of visits to enable access to cultural rights and operate in the affirmation and construction of the habitus.

Keywords: Young. Rights. Cultural spaces. Habitus. Social Psychology.

\section{Jóvenes estudiantes y visitas en espacios públicos y culturales: com- promiso, trans-formación de habitus y construcción de significados}

Resumen: Este artículo comparte reflexiones construidas a partir de la investigación doctoral en Psicología Social que investigó la práctica de visitar a jóvenes estudiantes de escuelas públicas a instituciones artísticas y culturales de la Región Metropolitana de Belo Horizonte. El acceso a los espacios públicos, culturales y manifestaciones artísticas se sitúa históricamente tanto desde la perspectiva de la legislación relacionada con las políticas públicas como en las prácticas culturales de las instituciones que brindan acceso y experiencias con las artes en los equipamientos culturales. Considerando a los jóvenes como sujetos históricos y sujetos de derechos, se tienen en cuenta los significados que surgen de las entrevistas y conversaciones realizadas con los jóvenes estudiantes que participaron en las visitas. Estos significados fueron entendidos a través de un enfoque fenomenológico que, en su análisis, articuló los aportes teóricos de Pierre Bourdieu y Arnold Berleant, relacionados con los conceptos de habitus, campo estético y capital cultural. En la situación social encuestada, la práctica de la visitación, el involucramiento estético del observador-agente surge como una posibilidad para que los jóvenes ejerciten la reflexividad, interroguen e integren experiencias, construyendo significados que afirmen ambos el potencial de las visitas para posibilitar el acceso a los derechos culturales. y operar en la afirmación y construcción del habitus.

Palabras clave: Joven. Derechos. Espacios culturales. Habitus. Psicología Social.

\section{Introdução - Acesso às manifestações culturais como um direito: elementos históricos e contextos}

Após a Constituição de 1988, o Brasil experimentou a criação e a implementação de legislações direcionadas às políticas públicas no âmbito da Arte e da Cultura. Conforme explicita Gohn (2005), esse movimento foi iniciado gradativamente na área dos direitos humanos e ocorreu com o fim do regime militar. Segundo a autora, os movimentos e discussões nesse sentido ganharam amplitude após à promulgação da Constituição Federal estando associados aos temas da justiça e da equidade social.

Neste contexto de redemocratização, o Estado reconheceu os direitos culturais e assumiu responsabilidades em relação ao acesso e valorização das manifestações culturais. O artigo 215 da Constituição apresenta em sua redação que "O Estado garantirá a todos o pleno exercício dos direitos culturais e acesso às fontes de cultura nacional e apoiará e incentivará a valorização e difusão das manifestações culturais" (BRASIL, 2010). Este posicionamento propiciou importantes movimentos: o estado passou a reconhecer a relevância da área cultural oficializando sua responsabilidade em promover o desenvolvimento de políticas públicas específicas que pudessem materializar a promoção desses direitos. 
Neste contexto de transformações sociais e construção de "direitos culturais", documentos foram gestados e nortearam a implementação, acompanhamento e avaliação das políticas públicas na área cultural. Nas formulações de tais políticas, os termos cultura, direitos e cidadania foram articulados, e aos poucos foi se desenhando e consolidando uma política de Estado referente às questões relativas ao âmbito da cultura. Tal articulação não apenas redefiniu um entendimento sobre a área cultural, mas criou obrigações e direitos passíveis de mapeamento, monitoramento e avaliação no campo da cultura (BERG; GRAEFF; WAISMANN, 2015).

Um dos documentos que ilustra este processo é o Plano Nacional de Cultura ${ }^{1}-\mathrm{PNC}^{2}$ (BRASIL, 2007) que, nas últimas décadas, norteou a implementação de políticas públicas e práticas de instituições que difundem diferentes manifestações artísticas (BRASIL, 2007). Ele estabeleceu 53 metas a serem atingidas no período de 10 anos, entre 2010 a 2020. Uma delas, meta 28, o objetivo de promover e aumentar o número de pessoas que frequentam museus, centros culturais, cinema, espetáculos de teatro, circo, dança e música explicita o intuito de ampliar o acesso aos espaços mencionados nos quais acessam-se determinados bens culturais.

Neste artigo, não nos deteremos no conteúdo dessa extensa documentação referente aos bens culturais e as indagações surgidas ao longo de sua trajetória. A partir desses documentos e legislações, consideramos fundamental examiná-lo sem relação aos contextos e transformações históricas e sociais derivados das práticas e representações resultantes do campo da cultura. A esse propósito ressaltamos que a ideia de que existem "bens culturais" e "direitos culturais" foi aos poucos sendo difundida e estimulou muitas práticas, dentre as quais aquelas constituídas pela visitação e fruição das artes nos "espaços culturais" apenas o discurso acerca do acesso aos equipamentos culturais, mas, sobretudo, os significados atribuídos pelos usuários, neste caso, os jovens.

\section{Jovens como sujeitos de direitos}

No âmbito das formulações das políticas públicas e de sua operacionalização, os adolescentes e jovens passaram à condição de sujeitos de direitos com a Constituição de 1988. O paradigma dos direitos para este público e a reformulação das políticas sociais ganharam corpo mais detalhado com a criação do Estatuto da Criança e do Adolescente - ECA, em 1990, e do Estatuto da Juventude, em 2013.

\footnotetext{
1 Esses documentos foram elaborados pelos conselhos de política cultural, a partir das diretrizes definidas nas conferências de cultura, e tinham por finalidade o planejamento e a execução de políticas públicas de longo prazo para a proteção e promoção da diversidade cultural brasileira. Com a perspectiva de planejamento decenal, a expectativa era que tais planos fornecessem consistência ao SNC, constituindo-se em instrumento essencial no processo de institucionalização das políticas públicas de cultura no País. Nessa perspectiva, em 2010, o Poder Legislativo aprovou o primeiro PNC. A concepção do PNC partiu de uma perspectiva antropológica e propôs a compreensão e o reconhecimento das manifestações da cultura brasileira em três dimensões: simbólica, cidadã e econômica. Ao expor tais dimensões, o PNC relacionou-as com a valorização das múltiplas expressões culturais, com a qualidade de vida e com o fortalecimento de laços identitários entre os brasileiros. Além disso, o documento ressalta as cadeias produtivas e compreende os bens culturais como elementos capazes de impulsionar e movimentar a economia.

2 É necessário mencionar que, tais legislações operam por meio do poder executivo que atua por meio de pastas ou ministérios que, na recente história brasileira, tem atravessado intensas mudanças. De 1985 a 2016 existiu um Ministério da Cultura, entretanto em 2016, com o impeachment presidencial este Ministério passou por processos intensos de transformação, chegando, nesta época, a ser reduzido a uma pasta ministerial dentro do Ministério da Educação. Tal ocorrência levou a inúmeras manifestações pelo País nas quais a classe artística e outros agentes culturais mobilizaram-se no sentido de pressionar o poder público a retomada do Ministério da Cultura. Tal condição foi novamente alterada em 2019 com a mudança governamental que aglutinou os Ministérios da Cultura, do Desenvolvimento Social e do Esporte ao recém-criado Ministério da Cidadania. Em 2020 foi criada a Secretaria da Cultura dentro do Ministério do Turismo. Ainda não é possível dimensionar os impactos e prejuízos destas modificações na continuidade e desenvolvimento de políticas públicas no âmbito da cultura. Mesmo neste cenário de intensas mudanças e incertezas consideramos que é importante ressaltar que a ideia do acesso às manifestações culturais enquanto um direito capilarizou-se nos discursos e nas práticas de seus agentes no transcorrer do período histórico mencionado anteriormente.

30 termo "espaços culturais" é comumente utilizado pelas instituições artísticas e culturais ou mesmo pelas pessoas e comunidades para designar instituições que atuam na difusão e promoção das manifestações artísticas de arte e cultura, tais como: cinemas, teatro, museus, salas de exposição etc.
} 
Neste processo em que o jovem brasileiro foi ganhando condição de sujeito de direitos, ele foi gradativamente se constituindo em foco da atenção e atuação de instituições do poder público e da iniciativa privada, sendo possível identificar que diferentes segmentos sociais, como a escola, a academia, as redes institucionais, os legisladores, os meios de comunicação e a opinião pública, passaram a pensar as condições sociais, econômicas e culturais e os processos de inclusão e exclusão vivenciados por eles.

Como mencionado anteriormente, um dos documentos que traduz este processo é o Estatuto

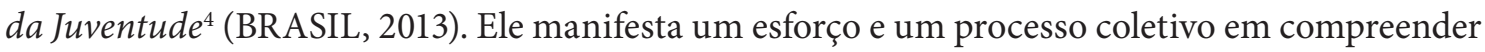
as diferentes condições desses cidadãos, situando-os em seus diferentes contextos e necessidades.

Dayrell (2011), ao identificar a juventude como uma categoria plural e dinâmica, argumenta que talvez seja mais pertinente pensar não em juventude, mas, sim, em jovens, como sujeitos que a experimentam e a sentem segundo determinado contexto sociocultural no qual se inserem. Além da compreensão das especificidades e da diversidade das condições sociais (origem de classe, por exemplo), culturais (etnias, identidades religiosas, valores etc.), de gênero e até mesmo geográficas enfatiza a importância de superar a ideia comumente difundida do jovem como um ser em transição.

Nesse sentido, alguns autores, na perspectiva de problematizar esta ideia de um ser em transição visibilizam as concepções que foram engendradas historicamente e veiculam modelos e expectativas que produzem formas de ser e agir, a partir de interesses produzidos em momentos culturais e sociais específicos (BOCK, 2007). Nesse sentido, Gonzalez e Guareschi (2014) detectam algumas concepções sobre os jovens que foram constituídas e predominaram nas últimas décadas. Apontam que eles já foram predicados de diferentes modos: como o "futuro do amanhã" (década de 1960); como revolucionários, militantes relacionados a movimentos de contracultura e vanguarda (após 1968); como aqueles mobilizados para questões sociais (movimento de Diretas já na década de 1980); como sujeitos associados a conflitos, excessos, a uma sociabilidade transgressora e violenta (década de 1990); como apáticos em relação às questões sociais e de mobilização coletiva (última década). Tais predicados costumam difundir visões restritivas e reducionistas e desenham equivocadamente concepções e práticas direcionadas a estes sujeitos que são, muitas vezes, orientadas por um pensamento desenvolvimentista que se ancora na cronologização da vida e na concepção de juventude como período de transição.

Na perspectiva de recuperar a capacidade de refletir e agir no mundo, notam-se, nos documentos norteadores em políticas públicas para juventude, proposições nas quais há valorização das experiências artísticas e culturais dos jovens e direcionadas ao público jovem. No texto da II Conferência Nacional da Juventude, ocorrida em 2011, a problematização relativa à formação artístico-cultural dos estudantes brasileiros é perceptível em trechos que expressam, por exemplo, a necessidade de pensar ações que provoquem mudanças no sentido de construir modos pelos quais os jovens constituam um grupo social atento e crítico para a recepção e produção de bens simbólicos.

\section{Visitas aos "espaços culturais": jovens como "público atingido" ou sujeitos de direitos?}

Na perspectiva de que os discursos e as práticas produzem outras realidades é notório que, nas últimas décadas, a ideia de "democratizar a arte e cultura" e de que "arte transforma vidas"

\footnotetext{
4 Em sua proposição por faixas etárias, por exemplo, 15 aos 29, para a condição de ser jovem, traz ressonâncias da cronologização da vida, mas ao mesmo tempo busca identificar e mapear as especificidades da pluralidade da experiência de ser jovem no Brasil: os jovens e suas diferentes classes sociais; os que vivem nas cidades ou no campo; os jovens brancos, negros e indígenas; os que estão na rede pública de ensino ou na rede privada; os jovens estudantes e ao mesmo tempo trabalhadores. São inúmeras e diversificadas condições, estratificações sociais e modos de ser que merecem investigação. Diante dessas múltiplas realidades, é fundamental compreender as práticas ou descrever processos que forneçam subsídios para a construção de ações que tomem em consideração as diferenças junto a esses jovens.
} 
tornaram-se enunciados habituais no discurso das instituições de educação formal e não formal e de muitos profissionais que atuam junto aos jovens brasileiros. A presença da arte e suas diferentes manifestações nos processos educativos e de socialização com os jovens passou a figurar como ação valorizada pelos profissionais da educação, seja por meio de oficinas de arte e educação ou por meio de visitas aos chamados "espaços culturais". Essas ações se apresentam atreladas à ideia de que os estudantes precisam ter outras situações de aprendizagem, de ampliação de conhecimentos e da promoção do direito à arte e à cultura.

Neste cenário de delimitação da área cultural e da proposta de impulsionar a economia por meio de suas manifestações, a arte é também compreendida como um produto, sendo também artigo de consumo. O consumo e a comercialização dos chamados bens culturais são fenômenos que ocorrem simultaneamente à valorização da prática de se apreciar arte e a constituição da percepção de certas categorias ou expressões artísticas. É pertinente destacar que tais aspectos encontram-se engendrados em processos históricos que se articulam na produção social do que compreendemos como arte (ANDRIOLO, 2010; WOLFF, 1982).

No contexto brasileiro, a constituição de muitos espaços que se propõem a democratizar o acesso aos chamados "bens culturais" ocorreu na esfera privada e também no terceiro setor. Deste modo, entidades, articuladas ao poder público, empresas, bancos e redes do comércio e da indústria, passaram a realizar os projetos junto à população visando a difusão dos chamados "bens culturais".

As associações, fundações e outras entidades nesse âmbito cultural fortaleceram-se ao tomarem a dianteira na organização da população e dos movimentos sociais, institucionalizando as práticas e organizações populares, na própria sociedade civil ou por meio de políticas públicas, ou estruturas organizativas criadas no próprio corpo estatal. Nesse processo, alguns termos e enunciados tornaram-se usuais no discurso destas instituições, como os de responsabilidade social, compromisso social, formação cidadã, empoderamento, protagonismo social, vulnerabilidade social, economia social entre outros. Recebendo apoio financeiro, privado e público, essas organizações passaram a trabalhar de forma diferente de como os movimentos sociais atuavam.

De acordo com Gohn (2011), a expansão da atuação do Terceiro Setor ${ }^{5}$ é um fenômeno que está atrelado aos movimentos sociais presentes no contexto brasileiro, nas últimas décadas. Essa autora destaca que, se, por um lado, inúmeras ações cidadãs foram realizadas, por outro, em sua análise, ocorreu um enfraquecimento dos movimentos sociais, tornando-os menos reivindicatórios e críticos. Nessas instituições de caráter cultural, vinculadas direta ou indiretamente ao poder público, as instituições de organizações civis e as da iniciativa privada, foi se tornando habitual a prática de constituir setores ou equipes que são nomeadas como "educativo", "pedagógico", sendo sua tarefa receber grupamentos de visitantes que são estudantes, em sua maioria.

No Brasil, os primeiros serviços educativos em museus que "orientavam para ver a arte" foram organizados nos anos 1950, no Rio de Janeiro. Na década de 1980, o museu Lasar Segall e o Museu de Arte Contemporânea (MAC) da Universidade de São Paulo (USP) influenciaram a formação de professores de arte, o interesse pelas visitas aos museus e a constituição dos educativos. Neste período, outros museus em várias capitais foram criados ${ }^{6}$ e Barbosa (2009) correlaciona tal crescimento tanto à incorporação dos princípios da "abordagem triangular" ${ }^{7}$ nos Parâmetros Curriculares Nacionais - PCNs - quanto a uma maior consciência social. Entretanto, além desses dois aspectos, ela pontua que o aumento da atenção dada à educação nos museus ocorreu,

5 É um termo sociológico utilizado para definir organizações de iniciativa privada, sem fins lucrativos e que prestam serviços de caráter público. 6 A autora destaca a criação dos educativos no Museu de Arte Moderna/SP, Museu de Arte moderna/RJ, Museu de Arte Contemporânea/Niterói, Museu de Arte do Rio Grande do Sul/Porto Alegre, Museu de Arte Moderna Aloisio Magalhaes/Recife, Centro Cultural Banco do Brasil (RJ, SP, Brasília), Instituto Cultural Itaú e nos museus de Belém, Curitiba, Belo Horizonte e Florianópolis.

7 A Abordagem Triangular desenvolvida por Ana Mae Barbosa propõe que o aprendizado de Arte acontece por meio de três ações básicas: Contextualização histórica (conhecer a sua contextualização histórica); Fazer artístico (fazer arte); Apreciação artística (saber ler uma obra de arte). 
também, quando as megaexposições evidenciaram que as escolas são o público mais numeroso nesses eventos, consequentemente "inflam as estatísticas e ajudam a mostrar grande número de visitantes aos patrocinadores" (BARBOSA, 2009, p. 17). A afirmação dessa autora nos coloca diante de um elemento importante que auxilia a compreender a grande expansão dos serviços educativos nos diferentes "espaços culturais" no Brasil: a necessidade de apresentar números ou resultados quantitativos em termos de público atingido, que pudessem justificar a importância da difusão de determinado tipo de manifestação cultural e/ou artística.

Considerando as ideias de Bourdieu (2013) sobre a composição da realidade social e suas distintas dimensões, compreendemos que uma delas refere-se ao que é quantificável, passível de estatísticas para apreender as disposições de propriedades materiais; e outra, que se relaciona às significações. Na apreensão da presente pesquisa, ao menos duas dimensões e/ou movimentos de formação circunscrevem o campo da prática de visitação, desvelando um jogo de forças. Nele, os jovens gravitam em torno de pelo menos dois possíveis predicados: constituir mais um número nas estatísticas de visitação ou constituírem-se sujeitos que se posicionam e refletem sobre suas experiências, negociam e constroem sentidos a partir de sua experiência sensível na e por meio da prática de visitação.

No intuito de circunscrever os autores e conceitos que nos auxiliaram a construir os resultados e reflexões da presente pesquisa, apresentaremos brevemente o conceito de habitus de Pierre Bourdieu e a ideia de que na constituição deste habitus ocorre o processo tanto de interiorizar práticas e também de exteriorizar sistemas e disposições antes incorporadas/constituídas; apresentaremos também a ideia do jovem estudante como um observador engajado no contexto de um determinado campo estético, conceito desenvolvido por Arnold Berleant.

\section{Contribuições de Pierre Bourdieu: exteriorização e interiorização do habitus}

Para compreender a noção de habitus em Bourdieu é importante conhecer sua noção de campo que pode ser pensada como relevante conceito para operar a análise das práticas específicas de um determinado espaço social. Nessa perspectiva, cada espaço corresponde a um campo específico (artístico, econômico, educacional, religioso, científico e jornalístico, entre outros), no qual constitui-se a posição social dos agentes que podem ser detentores de determinado capital, que pode ser econômico, social ou cultural.

Ao buscar compreender a relação entre as condições materiais de existência (capital econômico), as estruturas sociais, institucionais e a individualidade, Bourdieu (2013, p. 191) construiu o conceito de habitus, que ele descreve como:

[...] um sistema de disposições socialmente constituídas que, enquanto estruturas estruturadas e estruturantes, constituem o princípio gerador e unificador do conjunto das práticas e das ideologias características de um grupo de agentes.

As proposições teóricas e de pesquisa deste autor buscaram estabelecer uma mediação entre a estrutura socioinstitucional e a ação dos indivíduos que são nomeados por ele como "agentes". Esse conceito e sua articulação com outras formulações evidenciam o seu esforço em pensar a complexidade presente nos diferentes "campos", não reduzindo suas análises a uma compreensão na qual o modus operandi das estruturas determina a prática dos agentes, mas sim pensando esta relação entre estruturas e práticas numa via de mão dupla na qual a prática destes agentes pode tanto reproduzir como dialogicamente transformar determinada realidade ou estrutura.

O campo investigado na presente pesquisa, por exemplo, campo artístico e cultural, das práticas de visitação aos espaços públicos e culturais é atravessado por um mercado que produz 
bens culturais e consumidores. Nele, distribuem-se as instituições e os agentes. Considerando as ideias de Bourdieu, ao abordar as posições dos indivíduos ou agentes em determinado campo relacional, teremos em mente que a forma como consumimos, produzimos ou acumulamos, seja um produto material ou imaterial, determina as diferentes posições dos agentes nesses campos.

As instituições produtoras de determinados bens culturais elegem o que tem valor no campo; portanto, o capital que estará disponível. O campo é estruturado por relações de força entre os agentes e/ou as instituições e, nesse embate, gera a distribuição de capitais específicos. Nesse sentido, o campo torna-se o lugar onde os indivíduos pertencentes empreendem uma luta relativa ao capital, que pode ser econômico ou cultural, sendo habitado continuamente por relações de força entre seus agentes. E será a partir dessas relações, em diversos campos, que o habitus se constituirá. Nessa ótica, os agentes, apropriados desses capitais acumulados derivados de embates anteriores, podem estabelecer outras estratégias em atuações futuras noutros campos.

As ideias deste autor, no processo de pesquisa, foram importantes para pensar em que medida a prática de visitação constitui uma ação que pode reproduzir valores e hábitos de determinadas classes sociais e, também, em que medida os jovens, ao visitarem estes espaços encontram espaço para modificar e também exteriorizar seus sistemas e disposições anteriormente incorporados. Em suas formulações sobre o habitus, Bourdieu aponta esse conceito como princípio operador capaz de evidenciar a interação entre dois sistemas de relação: as estruturas e as práticas. O habitus, sendo o conjunto de disposições que tanto estão estruturadas, mas são também estruturantes, opera de maneira contínua, inter-relacionando as estruturas e suas condições objetivas e as situações conjunturais com as práticas exigidas. As interações que se dão em determinado campo constituem espaço potencial para que os agentes não apenas interiorizem estruturas exteriores, mas, também, possam exteriorizar sistemas e disposições incorporadas.

Dentre as discussões propostas pelos resultados das pesquisas e por meio das formulações teóricas deste autor, encontramos questionamentos sobre a ideia difundida de que a arte está acessível para todos. Esta ideia é por ele problematizada em textos contidos em sua obra $O$ amor pela arte (BOURDIEU; DARBEL, 2007) e nos permite pensar, por exemplo, que mesmo a entrada sendo aberta ao público, muitas vezes o sujeito nem mesmo vai entrar naquele espaço físico ou quando entra pode não se sentir autorizado a apreender ou interpretar diante de determinada manifestação artística. Este fenômeno parece estar relacionado ao habitus, as questões de classe social, à própria construção histórica de determinadas instituições que difundem o fazer artístico e como a convivência ou consumo de determinada modalidade artística operam como símbolo de distinção ${ }^{8}$ entre sujeitos de diferentes classes sociais. Então, a maneira como as pessoas se posicionam ou se apropriam destes espaços, que são considerados "públicos", é atravessada por questões relacionadas às classes sociais e a posição de classe, ao tipo de bens culturais e ao seu consumo. Consumir teatro, dança, artes visuais em museus pode conferir ou fazer operar o efeito de distinção.

Por outro lado, esta prática social, visitar "espaços culturais" pode ser pensada, também, como espaço de liberdade e de potencialidade para a transformação social, na medida em que consideramos as interações e a possível ação reflexiva destes jovens, por exemplo, compreendidos

8 Distinção é um conceito utilizado por Bourdieu e foi discutido em sua obra A distinção: crítica social do julgamento e também na Economia das trocas simbólicas (2013, p. 14). O autor apresenta um modelo de compreensão dos mecanismos sociais e culturais, que retira os fatores econômicos do centro das análises da sociedade, pois remete às práticas de consumo culturais a uma estrutura relacional. Argumenta que as práticas culturais juntamente com as preferências em assuntos como educação, arte, mídia, música, esporte, posições políticas, entre outros, estão ligadas ao nível de instrução, submetidas ao volume global de capital acumulado, aferidas pelos diplomas escolares ou pelo número de anos de estudo e, também à herança familiar. Com a discussão em torno da distinção operada por meio destas práticas culturais ele questiona a ideia de que o gosto é algo que não se discute, apontando que ele classifica; aproxima e afasta aqueles que experimentam os bens culturais, ou seja, opera distinguindo as pessoas, fortalecendo e intensificando a hierarquia do culturalmente aceito ou execrável; do autêntico ou do inautêntico. Por meio destes bens culturais eles constituem para os indivíduos marcas de distinção na relação com os outros e exprimem uma posição na estrutura social operando sobre valores vinculados à posição de classe. 
não apenas como visitantes que por ali passam, mas como como agentes no espaço social no contexto das visitas às instituições. Tal apreensão permite compreender que eles se posicionam diante das manifestações artísticas e utilizam seu conjunto de disposições anteriormente incorporadas (habitus) para relacionarem-se com as manifestações artísticas encontradas, o espaço físico das instituições, os profissionais dos "educativos" e o trânsito pela cidade.

Destarte, ao considerar o sentido relacionado às práticas dos agentes, em determinados contextos e o jogo de forças que se estabelece, notamos que as ideias de Bourdieu se fazem importantes na medida em que fornecem subsídios para compreender, também, que os jovens estudantes, como observadores, não estão passivos ou indiferentes durante a visita aos espaços.

\section{Contribuições de Arnold Berleant: o observador engajado e o campo estético}

Para aprofundarmos a compreensão dos achados de nossa pesquisa, além das considerações acerca de habitus e campo, originárias da sociologia da cultura de Bourdieu, acionamos o pensamento filosófico de Arnold Berleant, cuja contribuição possibilita recuperar a potência descritiva do conceito de aisthesis. Nesse sentido, propomos circunscrever nossa discussão partindo da ideia de uma percepção pelos sentidos. Este conceito, aisthesis, em sua retomada por autores contemporâneos no sentido da densidade da experiência perceptiva, tem sido muito importante na compreensão de fenômenos artísticos, embora não esteja circunscrito apenas ao campo das artes, tendo sido tomado por elas no transcorrer da história para descrever e compreender a chamada dimensão "estética" presente nestas experiências. Propomos partir da ideia de uma percepção pelos sentidos e desdobrá-la até o entendimento de uma percepção que se dá por meio da sensibilidade ou de uma consciência da experiência perceptual de diferentes fenômenos, não apenas aqueles relacionados às artes (BERLEANT, 1970). Deste modo, consideramos a experiência estética, circunscrita nesta compreensão primeira que designa o termo aisthesis, como a compreensão pelos sentidos que, em nossa perspectiva, pode ocasionar a construção de um "conhecimento sensível" e reflexivo sobre diferentes práticas sociais.

Berleant é um filósofo estadunidense que a partir de um rigor filosófico e de uma perspectiva fenomenológica dedica-se à compreensão do "campo estético" que é descrito por ele como sendo o contexto em que os objetos são apreciados (uma obra de arte, um prédio, uma paisagem, uma situação social) e são experienciados de forma ativa e criativa pelos seus participantes. Ele menciona que existem dois elementos principais que compõem esse campo e que geralmente são equivocadamente percebidos em separado: o observador-apreciador e o objeto observado. Observar esse campo implica a apreensão de uma situação social que inclua e considere esses elementos e a relação estabelecida entre eles. Para o autor é necessário considerar, também, a atividade ou evento que traz o objeto em foco para a existência (o artista, os processos da natureza, o ato de identificar um objeto de apreciação) e, por último, o fator que ativa o campo ou situação, como o performer ou o observador engajado. Com a ideia de um engajamento estético, ele expressa a ideia de que ocorre um envolvimento que integra todos os elementos dispostos neste "Campo Estético".

$\mathrm{Na}$ experiência dos jovens que investigamos, tomaremos a visita às instituições artísticas e culturais como a situação social que possibilitou trazer as manifestações artísticas ao foco de atenção e os jovens observadores engajados como fatores capazes de ativar este campo estético que, em nossa compreensão, não se restringiu ao espaço físico da instituição visitada, mas a esta situação social que inclui, também, a ação de sair da escola, deslocar-se e ocupar outros espaços da cidade. 


\section{Método: Fenômeno investigado, objetivos da pesquisa e escolhas metodológicas}

A pesquisa que movimenta o presente artigo investigou as relações, os sentidos construídos por jovens estudantes e por profissionais de ensino envolvidos na prática de visitação às instituições artísticas e culturais buscando situar a construção social e histórica do jovem como sujeito de direitos e o acesso às manifestações artísticas e aos bens culturais enquanto direitos. Na pesquisa de campo, foram realizadas conversas em grupo e entrevistas com profissionais da educação e jovens estudantes na perspectiva de compreender os sentidos construídos por aqueles que participaram das visitas em instituições artísticas e culturais. Neste texto focalizaremos os sentidos construídos pelos jovens estudantes. A pesquisa foi realizada com jovens de três escolas públicas da região metropolitana de Belo Horizonte que participaram de visitas agendadas por profissionais da escola. Ao todo foram acompanhados e ouvidos quatro grupos de estudantes, média de 25 a 30 estudantes em cada grupo, pertencentes ao 8 o e 9 o ano do ensino fundamental e 2 o ano do ensino médio. Esta atividade foi realizada em dias subsequentes às visitas aos espaços culturais. Foram também realizadas conversas com duas jovens estudantes que participaram de projetos sociais e educacionais que proporcionavam visitas a equipamentos culturais e públicos. Para confecção do presente artigo, consideraremos os enunciados de duas jovens que participaram das conversas em grupo e outra que foi entrevistada. Os nomes utilizados são fictícios.

Trabalhou-se na perspectiva da pesquisa qualitativa na qual a expressão dos sujeitos pode converter-se em aspectos significativos para a construção de conhecimentos por meio da negociação dos sentidos tecida no espaço de vida dos indivíduos, grupos e instituições (REY, 2002; SATO; SOUZA, 2001). A orientação metodológica ocorreu a partir da abordagem fenomenológica (AMATUZZI, 2009) na qual os participantes/pesquisados são compreendidos como colaboradores, pois não apenas fornecem informações, mas tratam do assunto com o pesquisador. A entrevista semiestruturada foi uma estratégia utilizada por compreender que esta é um processo de interação social, verbal e não verbal, que ocorre entre o pesquisador e o entrevistado. Buscou-se apreender os sentidos tecidos por meio da construção narrativa disparada pela seguinte questão: Quais sentidos são construídos por esses estudantes durante e a partir da experiência da visita? Com essas perguntas geradoras, a pesquisa se movimentou no diálogo com estudantes de escolas públicas, professores e educadores com experiência em educativos de "espaços culturais". No contexto do presente artigo, focalizaremos a expressão dos jovens estudantes e os sentidos construídos por eles a partir da prática de visitação.

Em diálogo com as formulações de Bourdieu e com a incursão pelo campo das legislações nas políticas públicas nas áreas artística e educacional que discorrem sobre os direitos culturais, entremeadas à ideia do jovem como um agente e/ou observador engajado, fomos desdobrando a indagação: em que medida a prática de visitação contribui nos processos de formação desses jovens, no sentido de provocar seus sistemas de disposições incorporados - o habitus? Recordando que, no entendimento aqui proposto, o habitus se dá numa relação dialética entre os jovens, os professores em suas relações nas instituições artísticas e culturais, entre uma dimensão que é individual e socioinstitucional dos campos educacional e artístico-cultural. Tal relação é permeada pelas ações desses jovens como agentes e/ou observadores engajados, sendo esta tanto estruturada como estruturante; isto é, deriva do jogo de forças entre um sistema de disposições sociais incorporada por esses jovens que se atualiza em meio aos estímulos e tensionamentos de uma circunstância ou situação relacional: a prática de visitação. 


\section{Resultados e discussão: A prática de visitação aos espaços culturais como possibilidade de os estudantes construírem sentidos, exercitarem a reflexividade, interrogarem e integrarem experiências}

Ao considerarmos as ideias de, relativas à experiência estética e as ideias de Bourdieu relativas ao habitus e ao capital cultural, intencionamos conjugar aspectos importantes que se encontram presentes na noção que adotamos de uma experiência estética: a experiência advinda de nossa percepção pelos sentidos, por uma sensibilidade que ultrapassa o sentido de simples sensação se referindo ao desenvolvimento da consciência da experiência perceptual, de nossa ação sensível no mundo que pode se transformar em conhecimento por empreender uma reflexão a partir do que se percebe (BERLEANT, 2017).

A prática de visitação torna-se reflexiva para estes jovens estudantes quando parte de sua sensibilidade ou relação sensível com as experiências e coloca em movimento não apenas a descrição de sensações, mas a necessidade de compreender tal experiência em um micro contexto e noutras vezes num macro contexto social. Noutras palavras, trata-se de performar um caminho ou movimento de transposição e articulação de ideias e pensamentos, de construção e transformação de um habitus que integra experiências de contextos diversos como o bairro em que se vive, a cidade que se habita ou encontra-se "interditada" e a instituição artística e cultural que se visita e as relações tecidas nesta situação social.

A articulação das contribuições destes dois autores parece propiciar um dos enfrentamentos que a Psicologia Social constantemente busca empreender: evitar a redução das explicações dos fenômenos sociais a análises individuais ou a análises coletivas. Ao contrário desta polarização entre o individual e o coletivo, numa perspectiva histórica e crítica ela precisa recuperar o indivíduo na interseção de sua história com a da sociedade na qual ele está inserido e ao fazê-lo, pode empreender um movimento que propicia transformações sociais (BOCK, 2007; LANE, 2012; SAWAIA, 2009).

Com o objetivo de elucidar o entrecruzamento de ideias e conceitos, exemplificando que a prática da visita a estes espaços pode engajar a sensibilidade destes jovens e propiciar a reflexividade, apresentaremos trechos advindos de nossos diálogos tecidos durante as entrevistas e reflexões nas conversas em grupo. Importante mencionar que os nomes dos participantes são fictícios.

Os jovens relataram que conhecer diferentes regiões e seus "espaços culturais" é uma prática que instigou novas percepções sobre a cidade, seus espaços e suas interações sociais. Nos trechos abaixo, a jovem Carolina relata seus deslocamentos pela cidade e ao mesmo tempo em que descreve um deslocamento físico revela que ele é também social. Ela diz:

[...] Como que parece bobo, mas muda... Eu nunca tinha ido ao Museu ou ao Parque das Mangabeiras. ... eu não sabia que eu podia entrar no Parque das Mangabeiras qualquer dia da semana e não tinha que pagar. Então eu comecei a sair lá de Venda Nova e vir pro centro. A gente fez várias visitas no Abílio Barreto (Museu) e Museu das telecomunicações. (Carolina).

Esta condição de distanciamento físico das oportunidades de trabalho, ensino e lazer dos jovens que estão localizados nas periferias dos grandes centros e a impossibilidade de acessarem serviços públicos é descrita por Dayrell e Carrano (2014) como uma espécie de aprisionamento social, no qual os jovens estão enclausurados em bairros periféricos. Conforme explicitam estes autores “[...] são muitos jovens aprisionados no espaço e no tempo, presos em seus bairros periféricos e com enormes dificuldades para articularem projetos de vida" (p. 127).

No relato de Carolina, a participação em oficinas de arte e educação, como a de construção de bonecos e de artes visuais, são mencionadas por ela como significativas neste percurso de apropriação das oportunidades educativas em instituições culturais da cidade. 
Tinha o teatro, eu participei da Mostra... teve uma experiência que ficou que foi aquele boneco gigante de arame. Eu tava naquela equipe que foi uma Mostra no espaço 104. Foi uma coisa que ficou marcada, nós fizemos um vídeo com as oficinas de áudio visual, falando sobre a interação da juventude na sociedade, sobre as profissões, como que cada profissão interage. Nesse momento da minha vida foi que eu cresci muito, assim, culturalmente falando [...]. (Carolina).

Uma das problematizações e críticas tecidas por Bourdieu, relativas às experiências dos indivíduos nas instituições, é a de que se pode ocupar fisicamente um espaço sem habitá-lo caso o indivíduo não possua um determinado habitus. A experiência deslocada em determinado espaço decorre da entrada sem preencher as condições que este exige de seus ocupantes. Demanda a posse de determinado capital cultural, que pode interditar a sua experiência com determinados bens culturais, ainda que estes sejam dados como públicos. Contrariamente, a experiência de habitar e construir um habitus pode também ocorrer.

Carolina, ao encadear suas experiências tanto na condição de visitante como na de proponente do fazer criativo, nas oficinas de vídeo ou de criação de bonecos, colabora no sentido de pensarmos que vai integrando tais experiências e posições, constituindo um habitus e um capital cultural relativo aos espaços e as manifestações artísticas. Seu depoimento apresenta a constituição de suas matrizes de percepção diante de espaços culturais instituídos e de como se sente apta a se apropriar deles a ponto de compartilhá-los com outras pessoas. Ouvir os sentidos trazidos por ela é ouvir como significa tal experiência, como ela opera subjetivamente, como é provocada neste campo ou espaço social.

Quando perguntada sobre possíveis contribuições do que já viu ou assistiu em sua formação ela descreve a existência de atribuições de gênero que ainda posicionam a mulher em papel social restrito a ser mãe e dona de casa, o que ela denomina como "uma cultura presa" das pessoas com as quais convive onde reside: "[...] onde eu vivo, acho que a cultura é muito presa, por exemplo, eu como mulher, eu tenho que arrumar um marido..." (Carolina).

Falar das experiências sobre os espaços visitados a faz revisitar sua trajetória familiar. Ela segue, citando o exemplo das tias que engravidaram sem planejar na adolescência. Ela parece afirmar como tem buscado outros caminhos e outras escolhas que permitam condições de agir a partir do que delibera que quer e não pelos atravessamentos do "destino".

As experiências com o teatro e as exposições fotográficas são descritas por ela como relações que catalisam outros desejos e motivações, outras buscas e "viagens". Falar das visitas a faz relembrar outros espaços e papéis sociais que gradativamente passou a habitar como a graduação em Engenharia Civil e a atuação como professora de Química. Ela afirma o espaço social da escola como ambiente no qual os conhecimentos precisam fazer sentido para aqueles que aprendem, deve apresentar relação com a vida.

A ideia de se aproximar de serviços e outros bens culturais encontra-se enunciada em outros trechos da conversa com Carolina:

A partir do momento que eu comecei a ver que eu poderia ter novas experiências, poderia aprender mais, poderia ser quem eu queria e não o que os outros queriam que eu fosse, eu comecei a ter mais autoconfiança... a partir do momento que eu comecei a ver novas realidades, comecei a sair. Eu comecei a olhar diferente. (Carolina).

O trânsito entre a escola e os "espaços culturais" e a relação com as manifestações artísticas parecem constituir um contexto potencial para ela formular indagações sobre sua vida, sobre o papel do professor e da escola e o quanto acessam de forma restrita os espaços da cidade. Ao se deixar afetar pelas situações sociais (exposições, mostras), pelas manifestações artísticas (fotografias, bonecos) Carolina relata alterações em seu sistema de disposições, seus valores e em seu projeto de vida. 
Santos (2012), ao problematizar as oportunidades e a desigualdade de acessos às oportunidades e direitos, lembra-nos que "Cada homem vale pelo lugar onde está: o seu valor como produtor, consumidor, cidadão depende de sua localização no território...” (p. 107). Deste modo, a possibilidade de ser mais ou menos cidadão depende do ponto do território onde se está, destacando que as oportunidades não são as mesmas. A cultura ou os processos culturais presentes na cidade constituem uma herança, mas também são parte de um reaprendizado das relações entre o homem e seu meio, um resultado obtido por meio do próprio processo de viver e interagir nestes espaços. Estas relações são construídas nos diferentes territórios nos quais vivemos. O território apresenta-se então muito mais do que um conjunto de objetos, mediante os quais trabalhamos, circulamos, moramos, mas também um espaço simbólico.

É pertinente destacar que Carolina parece experimentar o que Berleant nomeia como um engajamento da sensibilidade, ou seja, não se trata apenas de uma descrição do que se observa na qual os órgãos do sentido são estimulados, mas também convocados e envolvidos em direção a uma reflexividade. Como exemplo, ela diz que a ação ou exercício de ver fotografias e fotografar, propiciou a ela olhar para diversidade cultural da cultura brasileira, perceber nossas matrizes históricas, pensar em sua própria história. "Eu viajava nas fotografias..." (Carolina). Ela menciona que no bairro e região onde nasceu e cresceu ainda está presente uma "cultura presa" alicerçada em valores patriarcais nos quais o casamento e a maternidade são comportamentos mais esperados e valorizados para a mulher desempenhar. Compreendemos que ela está se referindo a uma mudança em seu habitus por meio desse seu engajamento na relação com as manifestações artísticas que aparece atrelado a um reposicionamento de seu olhar em direção às suas escolhas, à sua história na interseção da história de outras mulheres de sua família e suas amigas que ela menciona não terem tido a oportunidade de acessarem tais experiências.

Vamos compreendendo os sentidos da "viagem" de Carolina por meio das fotografias. Ao tecer suas ideias, ao descrever as relações que estabelece a partir da prática de visitar espaços, conhecer diferentes manifestações artísticas no campo da fotografia, ela enuncia qualidades desta experiência. Esta situação social, a visita aos espaços artísticos e culturais e a participação em oficinas artísticas, descritas por ela, catalisam o engajamento de sua sensibilidade, arremessando-a num movimento reflexivo.

Noutro momento da pesquisa, conversando com jovens estudantes que discorreram sobre uma peça teatral assistida, eles narram como esta experiência os afetou, propiciando pensar nas escolhas que fazem e em algumas formas de aprisionamento a que os personagens e eles podem estar submetidos. Foram articulando a percepção da obra cênica às suas experiências prévias, movimento que instaurou uma narrativa reflexiva, ultrapassando a obrigação inicial de acompanhar os professores. Marcos e Erika recordam que a peça teatral retrata as histórias do jovem André, que parece não ter como escapar de um "destino" trágico previsto no discurso dos próprios pais. Durante o diálogo, expressam o medo de situações e contextos e situações de vulnerabilidade e, além de pensarem no que desejam pra si, também expressam seus receios em relação ao que pode ocorrer e ao que não desejam para seus amigos e até mesmo para seus filhos. Os jovens questionam discursos sociais que predeterminam o destino do protagonista da peça teatral, André, e ao mesmo tempo relacionam o desfecho trágico dele às condições precárias de sobrevivência, aos frágeis vínculos familiares, à falta de oportunidades dignas de trabalho que o levam ao trabalho no tráfico.

Em contraponto aos sentidos que confirmam e legitimam determinados espaços culturais situados em regiões centrais da cidade que veiculariam uma cultura "eleita" por determinadas classes sociais, os jovens também questionam espaços e manifestações culturais eleitas e compartilham experiências culturais que vivem em seu território. Citam locais frequentados e que para eles são legítimos, como os bailes funks, por exemplo. Chegam a citar também que outras pessoas de diferentes classes sociais, que nomeiam como "patricinhas e playboys" consomem a música das regiões da cidade consideradas periféricas ou frequentam os bailes. Nestes momentos parecem comunicar 
seu capital cultural que outras classes sociais desejam acessar e não possuem, apontando que seus territórios produzem cultura ou "bens culturais". Nesse sentido, explicitaram também os modos de funcionamento desses bailes destacando que são mais acessíveis aos jovens periféricos e estabelecem formas alternativas de operar como, por exemplo, por meio da entrada em troca de alimento não perecível, ou propondo eventos nos espaços públicos do bairro, tais como as ruas ou praças.

Ao discorrerem sobre a visita aos espaços culturais "eleitos" e aqueles legitimados em seus próprios territórios, os jovens como observadores engajados e/ou agentes empreendem uma prática que pode ser transformadora na medida em que erguem um movimento reflexivo. Ela pode abrigar a expressão de seus diferentes modos de ser, estar e pensar a cidade, mediante contato com multiplicidade de lugares que ocupam, das manifestações artísticas e ou culturais que acessam e por meio do diálogo sobre tais experiências. O que confere a esta situação social, visitas aos espaços públicos e culturais, a possibilidade de um exercício que é ético, ou seja, diz respeito a um ethos, um modo de ser e se relacionar como também político, na medida em que pode propiciar transformações na percepção e nas relações sociais do jovem com outros sujeitos e espaços sociais: com a cidade, seus territórios e diferentes "espaços culturais" e situações sociais.

Os apontamentos realizados pelos jovens sobre o modo de ocupação de diferentes territórios e suas instituições e aos bens culturais presentes neles nos remetem aos pontos de vista, sociológico e filosófico, de Bourdieu e Berleant, contribuindo para nomearmos as apreensões deles como agentes e observadores engajados. Sua ação ativa e criativa de observar e se deixar afetar pelas manifestações artísticas externalizando suas percepções durante as conversas, demonstram que questionam e refletem a partir de suas experiências anteriores e de suas disposições anteriormente construídas.

\section{Considerações finais}

Os resultados deste estudo põem em relevo as nuances das relações sociais que se abrem no contexto da prática de visitação com estes jovens cidadãos, apontando para tal prática como ação potencialmente capaz de provocar o dissenso e a construção de percepções que abrem frestas para a experiência reflexiva.

No contexto das formulações de Bourdieu sobre o habitus, pode-se pensar que as ações humanas ou práticas ultrapassam o presente imediato, referindo-se a uma mobilização prática de um passado e de um futuro inscritos no presente na condição de uma potencialidade objetiva. Desse modo, o entendimento do conceito de habitus não se restringe a expressar uma ordem social funcionando pela lógica da reprodução e conservação, mas também constitui essa ordem por meio de práticas nas quais e pelas quais os agentes posicionam-se e contribuem no fazer da história (SETTON, 2002). Reconhecendo, então, que as práticas humanas operam nesse jogo de tensionamentos entre um modo de ser que tanto reproduz e conserva os sujeitos dentro de uma ordenação social e outros modos nos quais os sujeitos reconhecem em suas ações uma ruptura com a mera reprodução de uma ordem social, previamente dada (classes, valores), apresentamos anteriormente alguns sentidos compartilhados por jovens estudantes de escolas públicas. Pensar o deslocamento geográfico dos estudantes da escola até os chamados "espaços culturais" que estão situados na área central da cidade de BH e na RMBH possibilita refletir suas relações com o espaço social onde residem e transitam, sobre suas relações com a cidade e seus espaços.

Durante as entrevistas com os jovens um sentido que mais de uma vez apresentou-se ao discorrerem sobre a prática da visita em "espaços culturais" da cidade foi um certo traçado no mapa da cidade, que parte das bordas, dos espaços situados às margens dela, em direção ao seu centro. Estar nesse centro, usufruir dos "bens culturais" que dispõe, dos serviços, das oportunidades de trabalho e lazer.

Em certa medida, visitar os espaços culturais instituídos e sua cultura "eleita" pode ser pensado como uma ação que reproduz os valores de outra classe social, diferente da experimentada 
ou preferida habitualmente pelos estudantes, como os bailes funks, por exemplo. Visitar determinados espaços artísticos e culturais pode conformar um sentido de afirmação de um habitus, podendo incorrer numa reprodução de valores sociais de uma "cultura eleita" a ser herdada. Ao mesmo tempo, há um reconhecimento por parte dos jovens de que tais espaços não constituem os únicos que veiculam cultura, havendo outros ambientes do próprio território como espaços de aprendizagem e nos quais o jovem estudante pode acessar um determinado tipo de capital cultural.

As práticas de visitação podem operar consagrando a distinção das classes cultivadas ao propor a transmissão da "cultura" supostamente acessível a jovens estudantes de classes sociais elitizadas. Assim, a prática de visitação aos chamados "espaços culturais" pode ter o efeito de fortalecer tal distinção, definindo e reproduzindo posições de classe. Entretanto, em igual medida, pode, com a ação que observa, indaga, questionar a experiência; ou seja, com a prática de seus agentes, pode reposicionar tal efeito. É possível reconhecer nas partilhas destes jovens que, transitar pelos territórios da cidade, deslocar e habitar tais espaços parece provocar e engajar sua sensibilidade num movimento reflexivo.

Diante das reflexões destes jovens foi possível reconhecer que a relação com a situação social de mover-se pelos territórios da cidade, visitar "espaços culturais", relacionar com as manifestações artísticas erigem um campo intersubjetivo no qual se dão a fusão e a fundação de horizontes, integrando experiências em diferentes espaços e tempos na história desses sujeitos.

Considerando este cenário no qual entrecruzam-se discursos das legislações vigentes e a experiência dos jovens nessa situação social, prática de visitação, a presente investigação aponta que, neste campo de interações, operam afirmações e transformações do habitus dos jovens. Além disso, em meio aos sentidos construídos por eles, no contexto da visita, consideramos que este estudo pode contribuir com a reflexão e construção metodológica das práticas das instituições culturais que trabalham no sentido de promover o acesso e a democratização dos direitos culturais. Os resultados apontam que tais instituições, em seu fazer cotidiano, ao acolher o habitus desses jovens estudantes poderá engajar a sensibilidade desses observadores-agentes catalisando seu posicionamento e sua expressão criadora. Esta atitude pode movimentar afetos, opiniões e sentidos, levando-os a construir outras relações em diferentes espaços sociais.

\section{Referências}

ANDRIOLO, Arley. A percepção da "arte barroca": psicologia social e recepção estética. In: AJZENBERG, Elza; MUNANGA, Kabengele (org.). Arte, Cidade e Meio Ambiente. São Paulo: MAC-USP/Programa de Pós-Graduação Interunidades em Estética e História da Arte, 2010. p. 95-109.

AMATUZZI, Mauro Martins Psicologia fenomenológica: uma aproximação teórica humanista. Estudos de psicologia, Campinas, v. 26, n. 1, p. 93-100, jan./mar. 2009. Disponível em: http://www.scielo.br/scielo.php?script=sci_arttext\&pi$\mathrm{d}=$ S0103-166X2009000100010\&lng=en\&nrm=iso. Acesso em: 8 jun. 2014.

BARBOSA, Ana Mae. Mediação cultural é social. In: BARBOSA, Ana Mae; COUTINHO, Rejane Galvão (org.). Arte e educação como mediação social e cultural. São Paulo: Ed. da Unesp, 2009. p. 13-22.

BERG, Oscar Augusto; GRAEFF, Lucas; WAISMANN, Moisés. Equipamentos culturais na região metropolitana de Porto Alegre: desafios e possibilidades de avaliação a partir das metas do plano nacional de cultura. Políticas Culturais em Revista, Salvador, v. 1, n. 8, p. 206-221, 2015. Disponível em: www.politicasculturaisemrevista.ufba.br. Acesso em: 7 abr. 2015.

BERLEANT, Arnold. The Aesthetic Field: A Phenomenology of Aesthetic Experience. 2. ed. Springfield: C. C. Thomas, 1970. (Cybereditions).

BERLEANT, Anold. O caso da estética social. In: GRUPO DE ESTÉTICA SOCIAL. [São Paulo], 6 jun. 2017. Disponível em: https:/grupoesteticasocial.wordpress.com/2017/06/06/o-caso-da-estetica-social-arnold-berleant/. Acesso em: 19 nov. 2019. 
BOCK, Ana Mercês Bahia. A adolescência como construção social: estudo sobre livros destinados a pais e educadores. Revista Semestral da Associação Brasileira de Psicologia Escolar e Educacional (ABRAPEE), São Paulo, v. 11, n. 1, p. 63-76, jan./jun. 2007.

BOURDIEU, Pierre. A economia das trocas simbólicas. São Paulo: Perspectiva, 2013.

BOURDIEU, Pierre; DARBEL, Alain. O amor pela arte: os museus de Arte na Europa e seu público. São Paulo: Edusp; Porto Alegre: Zouk, 2007.

BRASIL. Constituição. Emenda Constitucional n. ${ }^{\circ}$ 65, de 13 de julho de 2010. [Dá nova redação ao art. 177 da Constituição Federal, alterando os parágrafos VII e VIII e inserindo os interesses da juventude]. Brasília, DF: Presidência da República, 1988. Disponível em: http://www.planalto.gov.br/ccivil_03/constituicao/Emendas/Emc/emc65.htm. Acesso em: 18 nov. 2014.

BRASIL. Plano Nacional de Cultura: caderno de diretrizes gerais. Brasília, DF: Ministério da Cultura, 2007.

BRASIL. Lei no 12.852. Institui o Estatuto da Juventude e dispõe sobre os direitos dos jovens, os princípios e as diretrizes das políticas públicas de juventude e o Sistema Nacional de Juventude - SINAJUVE. Brasília, DF: Presidência da República, 2013.

DAYRELL, Juarez; CARRANO, Paulo. Juventude e escola. In: DAYRELL, Juarez; CARRANO, Paulo; MAIA, Carla Linhares (org.). Juventude e ensino médio: sujeitos e currículos em diálogo. Belo Horizonte: Ed. da UFMG, 2014. p. 111-134.

DAYRELL, Juarez. Introdução. In: DAYRELL, Juarez; Moreira, Maria Ignez Costa; STENGEL, Márcia (org.). SIMPÓSIO INTERNACIONAL SOBRE JUVENTUDE BRASILEIRA, 4., 2010, Belo Horizonte. Juventudes contemporâneas: um mosaico de possibilidades. Anais [...]. Belo Horizonte: Ed. da PUC Minas, 2011.

GOHN, Maria da Glória. Movimentos sociais na contemporaneidade. Revista Brasileira de Educação, Rio de Janeiro, v. 16, n. 47, p. 333- 361, maio-ago. 2011.

GOHN, Maria da Glória. Cidadania e direitos culturais. Katálysis, Florianópolis, v. 8, n. 1, p. 15-23, jan./jun. 2005.

GONZALEZ, Zuleika Köhler; GUARESCHI, Neuza Maria de Fátima. Concepções sobre a categoria juventude: paradoxos e as produções no modo de ser jovem. In: CRUZ, Lílian Rodrigues da; GUARESCHI, Neuza. Políticas Públicas e Assistência Social: diálogos com as práticas psicológicas. Petrópolis: Vozes, 2014. p. 104-123.

LANE, Silvia Tatiana Meurer. A Psicologia Social e uma nova concepção do homem para a Psicologia. In: LANE, Silvia Tatiana Meurer; CODO, Wanderley (org.). Psicologia Social: O homem em movimento. São Paulo: Brasiliense, 2012.p. 11-19.

REY, Fernando Luis González. Pesquisa qualitativa em Psicologia: caminhos e desafios. Tradução Marcel Aristides F. S. São Paulo: Pioneira Thomson Learning, 2002.

SANTOS, Milton. O espaço do cidadão. São Paulo: Ed. da USP, 2012.

SATO, Leny; SOUZA, Marilene Proença Rebello. Contribuindo para desvelar a complexidade do cotidiano através da pesquisa etnográfica em Psicologia. Psicologia USP, São Paulo, v. 12, n. 2, p. 29-47, 2001.

SAWAIA, Bader Burihan. Psicologia e desigualdade social: uma reflexão sobre liberdade e transformação social. Psicologia e Sociedade, Florianópolis, v. 21, n. 3, p. 364-372, dez. 2009. Disponível em: http://www.scielo.br/scielo.php?script=sci_arttext\&pid=S0102-71822009000300010\&lng=en\&nrm=iso. Acesso em: 8 abr. 2015.

SETTON, Maria da Graça Jacintho. A teoria do habitus em Pierre Bourdieu: uma leitura contemporânea. Revista. Braileira de. Educação, Rio de Janeiro, n. 20, maio/ago. 2002. Disponível em: http://www.scielo.br/scielo.php?scrip$\mathrm{t}=$ sci_arttext\&pid=S1413-24782002000200005\&lng=en\&nrm=iso. Acesso em: 19 nov. 2015.

WOLFF, Janet. A interpretação como recriação. In: WOLFF, Janet. A produção social da arte. Rio de Janeiro: Zahar Editores, 1982. p. 110-131.

Data de submissão: 31/01/2021

Data de aceite: 03/02/2021 
Jovens estudantes e visitas em espaços públicos e culturais...

390 > Cadernos do Aplicação | Porto Alegre | jan.-jun. 2021 | v. 34 | n. 1 